Proceedings of the International Symposium on Physics of Materials (ISPMA 14), September 10-15, 2017, Prague

\title{
Heterogeneous Precipitation of the $\alpha$-Phase in Ti15Mo Alloy Subjected to High Pressure Torsion
}

\author{
K. Bartha ${ }^{a, *}$, J. StrRáskÝ ${ }^{a}, \mathrm{P}$ Harcuba $^{a}$, I. Semenova ${ }^{b}, \mathrm{~V} . \mathrm{Polyakova}^{b}$ \\ AND M. JANEČEK ${ }^{a}$ \\ ${ }^{a}$ Department of Physics of Materials, Charles University, Ke Karlovu 5, 121 16, Prague, Czech Republic \\ ${ }^{b}$ Institute of Physics of Advanced Materials, UFA State Aviation Technical University, \\ K. Marx Street 12, 450 000, Ufa, Russia
}

\begin{abstract}
Ti15Mo alloy is a binary metastable beta titanium alloy with excellent mechanical properties and biocompatibility. Therefore, it can potentially replace the most commonly used Ti6Al4V alloy in biomedical applications. Further processing of the alloy by the methods of severe plastic deformation provides an opportunity to achieve exceptional grain refinement and to enhance mechanical properties. Another way how to increase the strength of the alloy is thermomechanical processing which leads to the formation of the $\alpha$-phase. $\alpha$-phase is known to precipitate heterogeneously, in particular at grain boundaries. Refinement of parent $\beta$ matrix therefore affects the size and the morphology of $\alpha$ precipitates. Ultrafine grained Ti15Mo alloy was processed by high pressure torsion. The precipitation behavior of ultrafine grained and benchmark coarse-grained material during isothermal ageing was investigated by ex situ scanning electron microscopy. In the coarse-grained material the $\alpha$-phase precipitates both as grain boundary $\alpha$-phase and as acicular $\alpha$-phase inside the $\beta$-grains. On the other hand, in ultrafine grained alloy, only equiaxed sub-micrometer $\alpha$ particles precipitated at dense network of grain boundaries.
\end{abstract}

DOI: 10.12693/APhysPolA.134.790

PACS/topics: 61.66.Dk, 61.72.Mm, 64.60.My, 64.70.kd

\section{Introduction}

Metastable $\beta$-titanium ( $\beta$-Ti) alloys are extensively used in many applications thanks to their excellent mechanical properties, such as high strength, good ductility, and biocompatibility $[1,2]$. High-strength state of these materials is achieved by controlled precipitation of the $\alpha$-phase during thermomechanical processing [3]. $\alpha$ phase precipitates are usually heterogeneous in $\beta$-Ti alloys. On the other hand, the fundamentals of the Orowan strengthening stipulate [4] that the maximum strength is achieved by homogeneous distribution of fine precipitates. The main possibility to promote uniform precipitation of the $\alpha$-phase is to generate a large number of preferred nucleation sites including lattice dislocations, grain boundaries $(\mathrm{GB})$, sub-grain boundaries and interfaces between $\beta$ matrix and secondary phases such as $\omega$ and $\beta^{\prime}[3,5]$. The numerous nucleation sites prevent the coarsening of the $\alpha$-phase [6].

The precipitation morphology of the $\alpha$-phase in a common CG Ti15Mo alloy was investigated in [7]. It was shown that acicular (elongated) $\alpha$-phase forms inside grains. In the CG material, the large $\alpha$-phase precipitates along grain boundaries are considered adverse [8], as they do not strengthen the material significantly, and deteriorate the fatigue resistance of the alloy. Moreover, in UFG materials with grain sizes below $1 \mu \mathrm{m}$, the grain boundaries provide sufficiently dense network for very fine precipitation of the $\alpha$-phase.

*corresponding author; e-mail: bartha.kristina@gmail.com

Several studies reported that distinct shear bands (SBs) form during severe plastic deformation in Ti15Mo alloy [7] and Ti20Mo alloy $[9,10]$. Inside the SBs, the nucleation and growth of the equiaxed $\alpha$-phase is promoted reportedly due to the high density of nucleation sites (dislocations, lattice defects) and longer diffusion path.

Numerous studies, e.g. [10-13] indicate that microstructure refinement of $\mathrm{Ti}$ and biomedical $\mathrm{Ti}$ alloys processed by SPD methods increase their strength, hardness, and fatigue resistance. Deformation by high pressure torsion (HPT) [14] was employed in our recent study to achieve large induced deformation, high density of dislocations and exceptional grain refinement $[15,16]$. The main aim of this study is to investigate the morphology of $\alpha$-phase precipitates in SPD deformed Ti15Mo alloy by HPT $(N=1)$ and the effect of the chemical composition on the nucleation and growth of the $\alpha$-phase.

\section{Materials and methods}

Ti15Mo alloy, in the form of a rod with the diameter of $10.5 \mathrm{~mm}$, was solution treated $\left(810^{\circ} \mathrm{C}, 20 \mathrm{~min}\right)$ in a protective $\mathrm{Ar}$ atmosphere followed by water quenching. Subsequently, it was cut to cylinders (height approximately $5 \mathrm{~mm}$ ) and subjected to HPT deformation under $8 \mathrm{GPa}$ pressure at room temperature to obtain the disc-shaped specimens of $20 \mathrm{~mm}$ in diameter and with a thickness of $1 \mathrm{~mm}$ [15-17]. Samples processed by a single HPT rotation were used for all observations presented in this study.

Scanning electron images using backscattered electrons were taken at Zeiss Auriga Compact SEM equipped with field emission gun (FEG) operated at $10 \mathrm{kV}$. Chemical 
composition was obtained by EDAX EDS. Samples for SEM observations were prepared by mechanical grinding and polishing followed by a three-step vibratory polishing. The final step included ion polishing using Leica EM RES102 ion polisher.

\section{Results}

Figure 1 shows the microstructure at the periphery of the sample of Ti15Mo alloy after 1 turn of HPT processing. The contrast of the picture is given by a chemical composition (black dots are the artifacts of the mechanical grinding and polishing and should be neglected). Dark bands (DBs) between light regions (LRs) are clearly visible on the image. The chemical composition of the DBs and LRs (marked as A and B in the image) is different as proven by EDS measurements which are summarized in Table I. The microstructure of the Ti15Mo alloy after deformation by HPT (sub-micrometer $\beta$ grains cannot be resolved) and of the condition after HPT and subsequent annealing at $500^{\circ} \mathrm{C}$ for $16 \mathrm{~h}$ are shown in Fig. 2a and b, respectively. In Fig. 2a, DBs and LRs are clearly visible. Dotted structure in Fig. $2 \mathrm{~b}$ is caused by precipitation of refined $\alpha$-phase particles (shown also in detail in Fig. 3b). Darker and lighter areas caused by different size (and possibly also volume fraction) of the $\alpha$-phase precipitates can be recognized in the SEM micrograph in Fig. 2b.

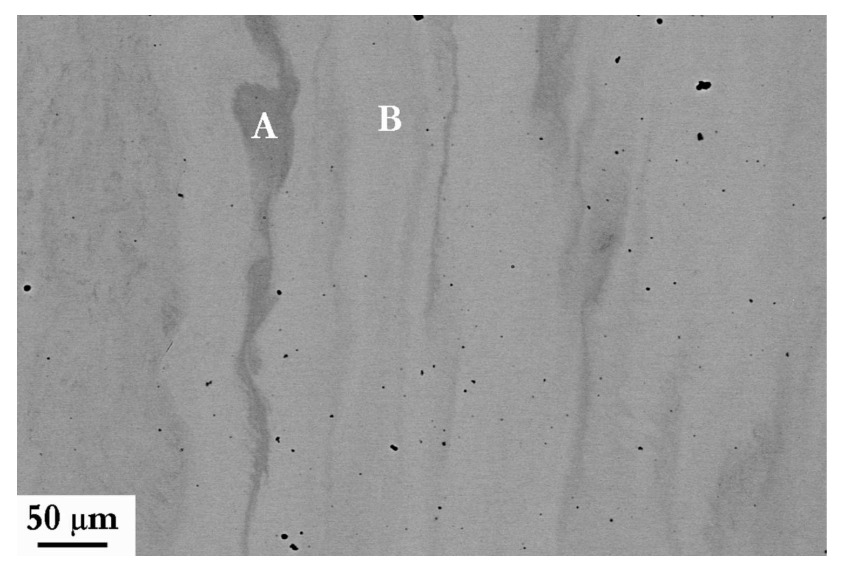

Fig. 1. SEM backscattered electron image of Ti15Mo alloy after HPT processing. Letters A and B indicate the place of the chemical composition analysis (black dots are the artifacts of the sample preparation for SEM observation).

TABLE I

Chemical composition of the places marked as letter $\mathrm{A}$ and $\mathrm{B}$ in Fig. 1, measured by EDS

\begin{tabular}{c|c|c}
\hline \hline & Element & wt\% \\
\hline \multirow{2}{*}{$\mathrm{A}$} & $\mathrm{Ti}$ & 85.65 \\
& $\mathrm{Mo}$ & 14.35 \\
\hline \multirow{2}{*}{$\mathrm{B}$} & $\mathrm{Ti}$ & 83.26 \\
& $\mathrm{Mo}$ & 16.74
\end{tabular}
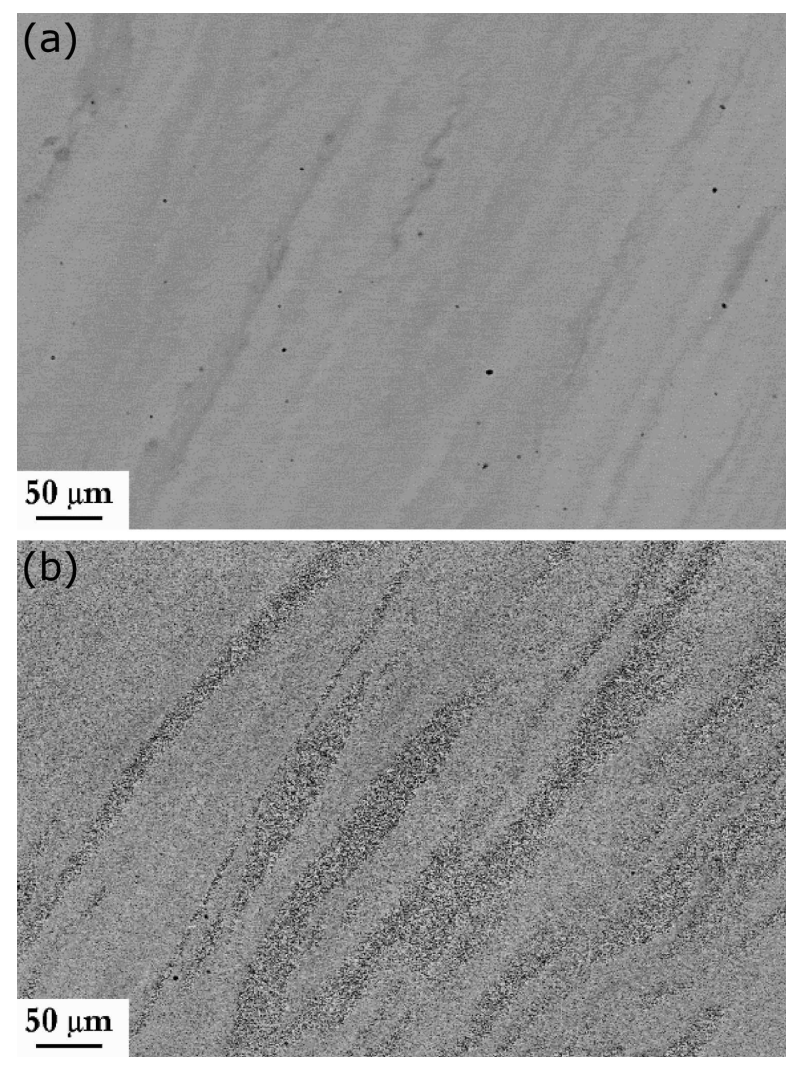

Fig. 2. (a) SEM backscattered image of the Ti15Mo alloy processed by HPT in the as-deformed condition. (b) SEM backscattered image of the Ti15Mo alloy processed by HPT and subsequent annealing at $500{ }^{\circ} \mathrm{C}$ for $16 \mathrm{~h}$.

Figure 3 displays detailed SEM images of the Ti15Mo alloy in the solution treated (ST) condition and annealed at $500{ }^{\circ} \mathrm{C}$ for $16 \mathrm{~h}$ (Fig. 3a) and in the HPT deformed condition after annealing at $500^{\circ} \mathrm{C}$ for $16 \mathrm{~h}$ (Fig. 3b). In Fig. 3a, the non-uniform distribution of large $\mathrm{GB} \alpha$ precipitates in the $\beta$ matrix is shown. In the interior of $\beta$ grains, two types of precipitates: acicular $\alpha$-phase platelets [7] and some finer equiaxed $\alpha$ precipitates are clearly visible. The annealed HPT deformed Ti15Mo alloy with UFG microstructure contains equiaxed submicrometer $\alpha$-phase. Figure $3 \mathrm{~b}$ indicates qualitatively that the volume fraction of $\alpha$ precipitates is apparently lower in lighter regions.

\section{Discussion}

This study demonstrates that the HPT process significantly changes the precipitation behavior of the $\alpha$ phase in Ti15Mo alloy during annealing. Firstly, refined $\beta$ grains [18] provide plenty of homogeneously distributed preferential nucleation sites. Secondly, it is evident that the formation of the UFG duplex $(\alpha+\beta)$ structure is closely correlated with the bands that appear dark and light in SEM images and were induced by HPT deformation. Figure 1 shows the structure of the HPT deformed 

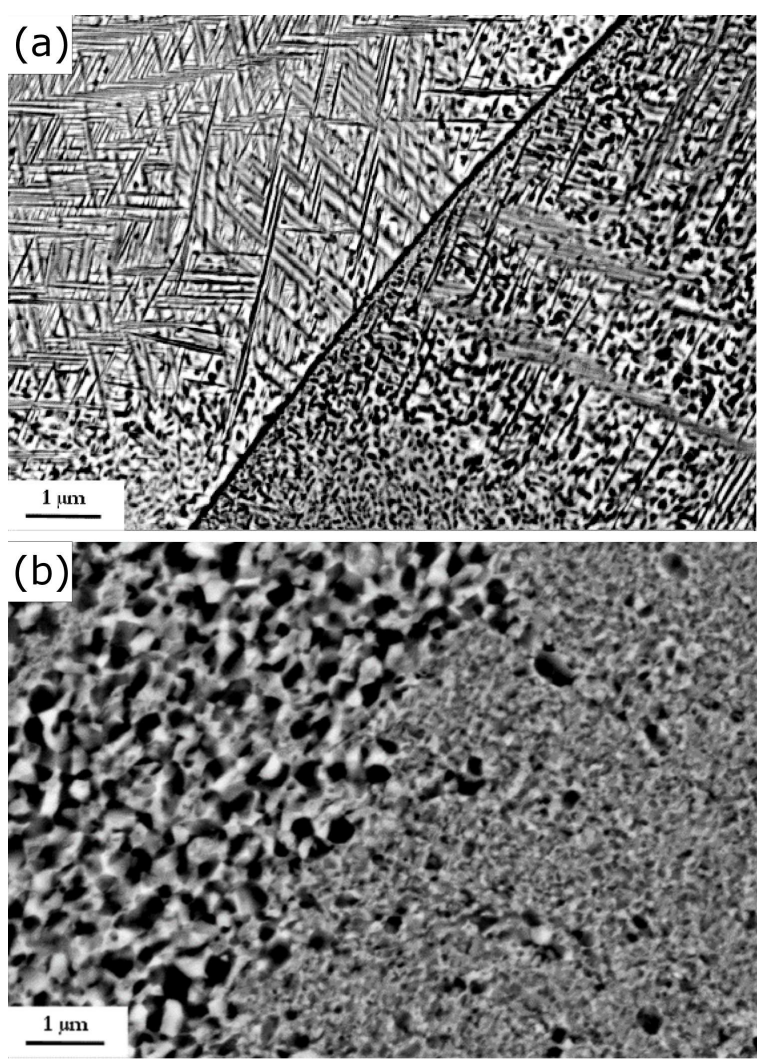

Fig. 3. (a) Detailed SEM backscattered image of the Ti15Mo alloy in the solution treated and annealed condition at $500{ }^{\circ} \mathrm{C}$ for $16 \mathrm{~h}$. (b) Detailed SEM backscattered image of the Ti15Mo alloy processed by HPT after annealing at $500{ }^{\circ} \mathrm{C}$ for $16 \mathrm{~h}$.

material. It was observed that DBs and LRs have different chemical composition (summarized in Table I). The DBs are oriented parallel to the direction of deformation, i.e. in HPT deformed specimens these bands form concentric circles (not shown here) [15]. Other studies claim that these "dark bands" are in fact shear bands with apparently enhanced density of lattice defects as compared to surrounding areas $[7,9,10,19]$. However, EDS investigation proved that these DBs characterized by lower amount of Mo (molybdenum is $\beta$-stabilizing element) are areas with appropriate conditions for easy precipitation and diffusion-controlled growth of the $\alpha$-phase. These observations, however, cannot rule out that DBs contain increased amount of lattice defects.

Figure $3 \mathrm{a}$ and $\mathrm{b}$ highlight the differences in the precipitation behavior of the CG Ti15Mo alloy and its UFG counterpart. In CG Ti15Mo $\alpha$-precipitates form special acicular shapes in order to reduce elastic distortion and create a coherent interface [20]. Moreover, this acicular morphology satisfies the Burgers orientation relation and may indicate the low interfacial energy [21]. Figure 3b shows the heterogeneous precipitation of the $\alpha$-phase in the UFG material. The $\alpha$ precipitation is accelerated in HPT deformed Ti15Mo alloy and $\alpha$ precipitates sizes are in sub-micrometer range due to the high amount of preferential nucleation sites [22].
The difference in the chemical composition (depletion of molybdenum), high density of dislocations and numerous grain boundaries acting as fast diffusion paths [10] are the possible reasons of the easier and equiaxed precipitation of the $\alpha$-phase in the DBs. Enhanced atomic transport contributes to the acceleration of $\alpha$-phase particles precipitation and growth [23]. As shown in our previous study [15], the dislocation density in HPT deformed Ti15Mo alloy exceeds $10^{14} \mathrm{~m}^{-2}$ already after a quarter of a turn. Detail experimental investigation is required to prove that dark bands contain higher density of dislocations and lattice defects.

\section{Conclusions}

The precipitation behavior of the $\alpha$-phase in the ultrafine grained Ti15Mo alloy processed by one turn of high pressure torsion and subsequently annealed at $500{ }^{\circ} \mathrm{C}$ for $16 \mathrm{~h}$ was studied and compared with the precipitation in coarse-grained material. The results may be summarized as follows:

1. High pressure torsion introduced a band-like structure to the material. The darker bands in between light regions differ in chemical composition — dark bands contain lower amount of Mo.

2. Upon isothermal ageing, coarse acicular and finer equiaxed $\alpha$-phase precipitated in the coarse grained material. On the other hand, only equiaxed $\alpha$ precipitates, sub-micrometer in size, were found in the ultrafine grained Ti15Mo alloy.

3. The size of the $\alpha$-phase is increased inside the dark bands, which is correlated with the easier nucleation and growth of the $\alpha$-phase in the dark bands.

\section{Acknowledgments}

This work was financially supported by the Czech Science Foundation under the project $17-20700 \mathrm{Y}$ and by the ERDF - project no. CZ.02.1.01/0.0/0.0/15_003/0000485. K.B. acknowledges financial support by the Grant Agency of Charles University project no. 1106216. M.J. and P.H. acknowledge financial support by the ERDF under the project CZ.02.1.01/0.0/0.0/15_003/0000485.

\section{References}

[1] R.R. Boyer, Mater. Sci. Eng. A 213, 103 (1996).

[2] M. Long, H.J. Rack, Biomaterials 19, 1621 (1998).

[3] T. Makino, R. Chikaizumi, T. Nagaoka, T. Furuhara, Mater. Sci. Eng. A 213, 51 (1996).

[4] E. Orowan, Zeitsch. Phys. 89, 605 (1934).

[5] S. Nag, R. Banerjee, R. Srinivasan, J.Y. Hwang, M. Harper, H.L. Fraser, Acta Mater. 57, 2136 (2009).

[6] M. Okada, ISIJ Int. 31, 834 (1991).

[7] B. Jiang, K. Tsuchiya, S. Emura, X. Min, Mater. Trans. 55, 877 (2014). 
[8] B.Y. Kokuoz, Y. Kosaka, H.J. Rack, JMEPEG 14, $773(2005)$.

[9] W. Xu, X. Wu, M. Stoica, M. Calin, U. Kühn, J. Eckert, K. Xia, Acta Mater. 60, 5067 (2012).

[10] W. Xu, D.P. Edwards, X. Wu, M. Stoica, M. Calin, U. Kühn, J. Eckert, K. Xia, Scr. Mater. 68, 67 (2013).

[11] M. Janeček, J. Stráský, J. Čížek, P. Harcuba, K. Václavová, V. Polyakova, I. Semenova, Metall. Mater. Trans. A 45A, 7 (2014).

[12] I. Semenova, A. Polyakov, V. Polyakova, Y.F. Grishina, Y. Huang, R.Z. Valiev, T.G. Langdon, Mater. Sci. Eng. A 696, 166 (2017).

[13] Z. Lin, L. Wang, X. Xue, W. Lu, J. Qin, D. Zhang, Mater. Sci. Eng. C 33, 4551 (2013).

[14] R.Z. Valiev, R.K. Islamgaliev, I.V. Alexandrov, Prog. Mater. Sci. 45, 103 (2000).

[15] M. Janeček, J. Čížek, J. Stráský, K. Václavová, P. Hruška, V. Polyakova, S. Gatina, I. Semenova, Mater. Character. 98, 233 (2014).
[16] K. Václavová, J. Stráský, V. Polyakova, J. Stráská, J. Nejezchlebová, H. Seiner, I. Semenova, M. Janeček, Mater. Sci. Eng. A 682, 220 (2017).

[17] R.Z. Valiev, A.V. Korznikov, R.R. Mulyukov, Mater. Sci. Eng. A 168, 141 (1993).

[18] K. Václavová, J. Stráský, J. Veselý, S. Gatina, V. Polyakova, I. Semenova, M. Janeček, Mater. Sci. Forum 879, 2555 (2017).

[19] A. Zafari, K. Xia, Scr. Mater. 124, 151 (2016).

[20] D.A. Porter, K.E. Easterling, Phase Transformations in Metals and Alloys, 2nd ed., Chapman and Hall, London 1992, p. 149.

[21] T. Furuhara, T. Makino, Y. Idei, H. Ishigaki, A. Takada, T. Maki, Mater. Trans. 39, 31 (1998).

[22] K. Václavová, J. Stráský, P. Zháňal, J. Veselý, V. Polyakova, I. Semenova, M. Janeček, IOP Conf. Series Mater. Sci. Eng. 194, 1 (2017).

[23] M. Legros, G. Dehm, E. Artz, T.J. Balk, Science 319 , $1646(2008)$ 